\title{
THE POSTAL SURVEY AS A RESEARCH TOOL IN NEW PROVIDENCE
}

By Joan Vanderpool \& William J. Fielding

https://doi.org/10.15362/ijbs.v12i0.52

\section{Abstract}

This paper describes two postal surveys conducted in New Providence between September 2001 and February 2002. These surveys, using the telephone directory as the sampling frame, were specifically designed to investigate the response rate to postal surveys in New Providence. Each survey included a one-page form sent to 250 persons resulting in a response rate of about 20\%. Each survey form contained one question that had also appeared in The Bahamas 2000 census. Overall response to this question differed significantly between the respondents to each survey and the respondents to the Census. These results suggest the presence of sources of bias relevant to the sampling frame, socio-economic status and self-selection. The implications of these results for using the postal survey as a research tool are discussed.

\section{Introduction}

In theory, the postal survey is an easily administered survey method, given a reliable list from which to select the sample (Anon, n.d.). It is also particularly useful when trying to contact a large number of respondents, or if the respondents are geographically dispersed (Survey and Statistical Research Centre, n.d.). It is also claimed that the postal survey is less expensive to administer than face-to-face interviews and so can allow a larger sample to be used (Manchester Information \& Associated Services, 2001). However, it is known that people are less likely to participate in postal surveys than face-to-face interviews or telephone surveys (Margetts \& Nelson, 1991). Thus, there is a trade-off between cost and response rate. Various methods have been employed to increase the response rate of postal surveys (paper colour, anonymity, incentives etc.) (Blankenship, Breen \& Dutka, 1998; Green, Boser, \& Hutchinson, n.d.; Pirotta, Gunn, Farish \& Karabatsos, 1999) most of which invariably increase the cost of the survey. Some techniques even failed to improve the response rate (for example Clerk, Khan and Gupta, 2001 investigated paper quality). A scan of postal surveys on the Internet relating to general populations (most studies are aimed at well-defined populations) gave 
Table 1. Example response rates from postal surveys.

\begin{tabular}{|c|c|c|c|}
\hline $\begin{array}{l}\text { Response } \\
\text { rate }\end{array}$ & Target & $\begin{array}{l}\text { WWW address } \\
\text { population }\end{array}$ & $\begin{array}{l}\text { Date WWW } \\
\text { s retrieved }\end{array}$ \\
\hline $55 \%$ & $\begin{array}{l}\text { General } \\
\text { population }\end{array}$ & $\begin{array}{l}\text { www.unavarra.es/directo/congresos/apoyo/ } \\
\text { EuroQol/05.pdf }\end{array}$ & $\begin{array}{l}3 \text { September } \\
2002\end{array}$ \\
\hline $52 \%$ & Electorate & $\begin{array}{l}\text { http://www.data-archive.ac.uk/findingData/sn } \\
\text { Description.asp?sn=3924 } 2002\end{array}$ & 3 September \\
\hline $51 \%$ & $\begin{array}{l}\text { Citizens } \\
\text { panels }\end{array}$ & www.camcnty.gov.uk/sub/ctnpanel/res0600/ & $\begin{array}{l}3 \text { September } \\
2002\end{array}$ \\
\hline $49 \%$ & Residents & $\begin{array}{l}\text { http://www.iuscrim.mpg.de/forsch/ } \\
\text { krim/oberwittler1_e.html2002 }\end{array}$ & 3 September \\
\hline $37 \%$ & Residents & $\begin{array}{l}\text { http://www.seftoncoast.org.uk/pdf/ } \\
\text { postal_sefton.pdf }\end{array}$ & $\begin{array}{l}3 \text { September } \\
2002\end{array}$ \\
\hline $35 \%$ & Electorate & $\begin{array}{l}\text { http://www.barnet.gov.uk/local_ } \\
\text { democracy/bvp/survey.pdf }\end{array}$ & $\begin{array}{l}3 \text { September } \\
2002\end{array}$ \\
\hline $35 \%$ & Households & $\begin{array}{l}\text { http://www.greydc.govt.nz/council/publications/ } \\
\text { Survey\%20Results.htm }\end{array}$ & $\begin{array}{l}3 \text { September } \\
2002\end{array}$ \\
\hline $34 \%$ & Graduates & www.nzvcc.ac.nz/pubaffpol/mr12022002.html & $\begin{array}{l}3 \text { September } \\
2002\end{array}$ \\
\hline $25 \%$ & Electorate & $\begin{array}{l}\text { http://forums.highland.gov.uk/welcome. } \\
\text { asp.locid-153011.fid-78.messagelD-1804.htm }\end{array}$ & $\begin{array}{l}3 \text { September } \\
2002\end{array}$ \\
\hline
\end{tabular}

response rates between $25 \%-55 \%$ (Table 1 ).

Unlike respondents to a national Census, respondents to a postal survey are not obligated to participate in a research study. They can decide for themselves whether or not they wish to answer questions or complete a form sent to them via the mail. Therefore, respondents in a postal survey are a self-selecting set of the sample population, and unless they are representative of the entire sample their responses will distort the information collected. Nonresponse is a concern because those who do not participate in a study might have responded differently than those who did, which could introduce bias into the results. Although it can be convenient to assume that respondents are similar to non-respondents, this may not always be so, hence the practice of using a mixed postal/telephone approach to data collection (Sheridan \& Strang, 1998).

Our mail delivery, while not unique to The Bahamas, contrasts with those countries which have a home delivery service and may affect the response rate to questionnaires sent by mail. Other than courier services, New Providence does not have a home delivery mail service. Mail is either delivered to post office counters (general delivery service), or post office boxes. According to the signage displayed in New Providence post offices during the period of this study, post office boxes in New Providence, depending on their size, have annual rental fees ranging between $\$ 30$ and $\$ 80$ per box.

The current total number of post office boxes in New Providence is 24,350 (Postmaster General's Office, personal communication, 2003). The ratio of the number of post office boxes in New Providence to the number of households in New Providence (Department of Statistics, 2002), is 1:2.5. 
As there is a cost associated with the rental of a post office box, it might be assumed that persons who have post office box addresses are wealthier than those who do not. In addition, due to the fact that demand for boxes is greater than supply, families and friends sometimes share one box, thus there is not necessarily a one-to-one relationship between box and household. Consequently, the person to whom the questionnaire is addressed might not have to incur the cost of a post office box. Indeed a review of post office boxes appearing in the telephone directory, reveals that there are some which recur several times. While this suggests that there are post boxes which serve many people either as groups or communities, it is not possible to determine the wealth (or other characteristics) of the persons sharing the boxes.

We are unaware of any study in The Bahamas that has attempted to examine or test the response rate of the postal survey. Therefore, this study was conducted to obtain an estimate of the response rate and to guide researchers who might consider using this method. A secondary objective was to look at the accuracy of the survey results.

\section{Method}

Two surveys were conducted via the post. One of the surveys addressed community issues with an emphasis on the environment (Appendix 1) and was posted in September 2001. The other survey addressed community issues with an emphasis on higher education in The Bahamas and was posted in October 2001 (Appendix 2). For the purpose of this study each of the survey questionnaires or forms had one question in common with a Census 2000 question. This question (question 9) related to the number of motor vehicles per household. The answer to this question would allow comparison between the surveys and the 2000 census results and so permit a 'check' on the comparability of the two sets of respondents and with the Census result.

The same method of selecting samples of 250 was used for each of the surveys conducted. The 2001 telephone directory was used as the source of addresses. For each page of the list of New Providence telephone numbers, one of the three columns was selected at random, and within the selected column a residential post office box address was selected at random. This method gave a sample size of 245. The remaining five addresses were obtained in a similar way after selecting five pages at random from the telephone book. Although we are aware that the selection of homes with a post office box could introduce bias into the sample, the primary objective of this study was to assess response rate.

It was decided to tag reply envelopes with the telephone exchange of the addressee for the survey on higher education. This identification would allow geographical variation in the response rate, if any, to be determined.

When forms were returned because the postal address was incorrect, they were re-sent only if an error had been made on the address. Faulty addresses were noted and the sample size reduced to obtain adjusted response rates. There was no additional follow-up to a non-responding household. 
Bearing in mind that the focus of this study is on the estimation of response, rather than the actual response to the questions (other than the "check" question) on the forms, we focus on response rates here. A summary of the actual responses is given in Appendix 1 (survey relating to community issues) and Appendix 2 (survey concerning higher education in The Bahamas). Replies received up to, and including the 4th February 2002 are included in both summaries.

\section{Survey concerning The College of The Bahamas}

A summary of the response rate is given in Table 2. Of the 250 forms posted, 20 , or $8.0 \%$, were returned due to incorrect post office box numbers, 44 forms were returned by respondents. The crude response rate was $17.6 \%$ and the adjusted response rate $19.1 \%$.

\section{Survey relating to community issues}

A summary of the returned forms is given in Table 2. Of the 250 forms sent out, 12 or $4.8 \%$ were returned due to the post office box number being incorrect, and 52 forms were completed, so the crude response rate was $20.8 \%$ and the adjusted response rate $21.9 \%$.

Table 2: A summary of responses from two postal surveys in New Providence

\begin{tabular}{lccccc}
\hline & Sample Size & $\begin{array}{c}\text { Wrong } \\
\text { address }\end{array}$ & $\begin{array}{c}\text { Adjusted } \\
\text { sample size }\end{array}$ & $\begin{array}{c}\text { Number } \\
\text { completed }\end{array}$ & \% response \\
\hline $\begin{array}{l}\text { Survey } \\
\text { concerning higher } \\
\text { education in }\end{array}$ & 250 & 20 & 230 & 44 & 19 \\
$\begin{array}{l}\text { The Bahamas } \\
\text { Survey relating } \\
\text { to community } \\
\text { issues }\end{array}$ & 250 & 12 & 238 & 52 & 22 \\
\hline
\end{tabular}

\section{Response by telephone exchange}

In Nassau, the telelphone exchange can be used as an indicator of respondent's place of residence, i.e. Delaport, Central Nassau etc. Of 250 survey forms sent out, the response by telephone exchange is summarized in Table 3. The number of survey forms returned due to incorrect addresses is an indicator of errors in the list which resulted from: (a) addressees being deceased and (b) listed post officer box holders having given up that box number.

\section{Number of motor vehicles}

Both surveys produced significantly different figures on the 'check' question. The 'check' question asked for the number of motor vehicles per household. While both sets of households had a modal number of two motor vehicles per household, none of the households in the study on issues relating to higher education in The Bahamas owned no motor vehicle, but $7.7 \%$ of households responding to the study on community issues owned no motor vehicle. One household in the study on issues relating to higher education in The Bahamas owned nine vehicles while the maximum in the other study was four. There was a mean number of 2.3 (se=0.23) motor vehicles per household from the survey concerning higher education in The Bahamas, and 1.7 (se=0.12) from the survey relating to community issues. These figures are significantly different at $\mathrm{p} \approx 0.01$, (the Mann-Witney test confirmed this difference, $\mathrm{p}=0.03$ ). 


\section{Discussion}

For completeness, the results of the surveys are included in the appendices. Other than the question relating to motor vehicles, they are not central to this study and are omitted from the discussion.

\section{Sample selection}

The samples used in the study were obtained by random selection of names in the telephone directory. This selection method therefore required individuals to have a listed telephone number. An alternative method of selection could have involved a random selection of post office boxes from each post office. While this method would have resulted in capturing households with ex-directory numbers, it would not be possible to send a personalized envelope and this might have further discouraged recipients from participating in the study. Further, if more than one household shared the same post office box, not all households with access to a post office box would be included in the sample. However, this method of selection could be investigated in future studies.

\section{External influences on response rate}

Two external events occurred during the period of this study. The first was the aircraft hijackings in America in September 2001, which diverted peoples' attention from daily matters. The second was the presence of anthrax in the American postal system, which caused concern here in October and November of 2001 and, interfered with postal deliveries within New Providence. Although the real effect these scares had may not have been great (National Association for Amateur Radio (2001) or Harvard School of Public Health (2001)), we did receive calls from concerned persons who wanted to verify that we had sent the letters before they opened them.

\section{Period of response}

No deadline had been set as to when the forms should be returned. There was no sense of urgency regarding return of the forms. Survey respondents continued to return survey forms up until the time the data collection was halted in February of 2002. We have no way of knowing if the prolonged period over which replies were received reflects the irregularity with which people empty their post office boxes. However, if people do visit the post office erratically, such a deadline might reduce the response rate, particularly if people find the survey questionnaire after the deadline. In another postal survey (which had a deadline) sent to business places in The Bahamas, it was found that all the responses arrived after the deadline. Moreover, considerable telephone follow-up was required to obtain any reply (Samuels, personal communication). As used in some market research surveys, a deadline, associated with a prize for replies received before the specified date, might increase the number of responses.

\section{Response rates}

Both surveys had similar response rates. Both were lower than those in Table 1 and at the lower end of the $20-30 \%$, which is the commonly expected response rate from postal surveys (Herek, 2002), but it should be noted that postal survey response rates can vary from $5 \%-50 \%$ for a one-shot mailing (Anon, n.d.). A postal survey sent to all households may result in an even lower response rate than found here, as delivery to post office boxes is considered 
more reliable. Our response rates are similar to that from a postal study seeking information for science and technology indicators in The Bahamas, which had a response rate of $20 \%$ from 74 organizations (Samuels, unpublished). However, that study included telephone follow-up and the replacement of questionnaires if requested.

Our rates of return do not allow us to infer much about the pattern of returns in different areas of New Providence, as classified by telephone exchange (Table 3). Overall, at least $6 \%$ of the addresses were incorrect; although not all incorrectly addressed forms may have been returned. Thus we can see that even a list, which is published yearly, rapidly becomes inaccurate.

Table 3. A summary of the crude response rate by telephone exchange to a postal survey in New Providence

\begin{tabular}{llcl}
\hline Exchange & \multicolumn{1}{c}{ Area } & No. completed & No. with wrong address \\
\hline 324 & Camperdown & 6 & 4 \\
\hline 341,361 & Carmichael & 2 & 4 \\
\hline $322,325,356$, & Central & 15 & 6 \\
\hline $326,328,323$ & Nassau & & 4 \\
\hline 362 & Coral Harbour & 4 & \\
\hline 327 & Delaporte & 3 & \\
\hline 364 & Lyford Cay & 2 & 2 \\
\hline 363 & Paradise Is. & 1 & 20 \\
\hline 392 & Pinewood Gds & 2 & \\
\hline 393 & Soldier Rd & 6 & 3 \\
\hline Not known* & & 44 & \\
\hline Total & & 1050 & \\
\hline
\end{tabular}

One respondent blanked out the telephone area code, two responses were not returned in the coded envelopes Areas are the exchange areas as defined by Batelco (undated).

\section{Biases in results and their possible source}

The sample list used here was the telephone directory. This is a public list and easily accessible. It should be noted that according to the 1990 census, $60.1 \%$ of households in New Providence had telephones (Department of Statistics, 1997). Even in 1998 there were 18,200 more telephone subscribers (Department of Statistics, 1999) than the number of households in 2000 (Department of Statistics, 2002). It might be safe to assume that more than $60 \%$ of households now have telephones, but disproportionately more poorer than richer households may yet not have telephones, and so the telephone directory might still be a biased list, in terms of household income.

Although the numbers in Table 3 are sparse, casual inspection suggests that the distribution of incorrect addresses is not uniform across all telephone exchanges. This could also introduce bias. The fact that households in our sample had access to a post office box in New Providence could result in a biased sample compared to the population of all households, in New Providence or throughout the country. This may explain the apparent differ- 
Both of the postal surveys gave the modal number of motor vehicles per household as two rather than the Census figure of one (Department of Statistics, 2002). This difference in results between the census and the postal surveys might result from the postal survey only making contact with wealthier households, or at least only getting results from wealthier households. The 2000 census data show that car ownership is a clear indicator of household income. Motor vehicle owning households have a median household income of $\$ 36,900$ per year, whereas in households with no motor vehicle the median household income is $\$ 13,700$ per year (Department of Statistics, personal communication, 2002). Alternatively, the list from which the postal samples were selected may include too many wealthier households, and so could be an unsuitable list to reflect all of New Providence.

No simple explanation can be offered for the apparent difference in the response in the surveys on the question about the number of motor vehicles owned per household or from the census results. Possible reasons for this finding might include: (1) Randomization was an inadequate protection against unknown sources of bias, (2) The subject matter of the two surveys may have appealed to different types of respondents. If the second reason is correct, the difference in mean number of motor vehicles per household may reflect bias due to self-selection of respondents connected with the subject of the survey. This is suggested by about $8 \%$ of the households responding to the survey on community issues not owning cars. This apparent self-selection may indicate the need for a mixed postal/telephone approach (although this modification cannot overcome any inherent defect associated with selecting households from the telephone list). That variant effectively becomes similar to a telephone study in which participants have been sensitized in advance of the telephone call, either by being sent the survey form or primer postcards. The importance of participants being given advanced notice of a study was found in a telephone survey on the referendum (Vanderpool, 2002), in which at least one person refused to cooperate because she had not "heard about it" in advance. Clearly, follow-up in the non-responding stratum would be useful and the results statistically adjusted (for example: Cochran,1977).

\section{Conclusion}

In a country fragmented by sea, a postal survey would appear to be an advantageous method to reach its dispersed population. However, this study suggests that a high level of non-response from a postal survey can occur. Despite similar response rates in both studies, there appeared to be bias in the results. Sources of these biases may be self-selection of the participants associated with the topic of the survey and bias due to economic characteristics of households responding to a postal survey. Follow-up via telephone may lead to higher response rates, as found by Samuels (unpublished).

It should be kept in mind that the focus of our study was the use of a particular research method when conducting research in New Providence. The paucity of literature concerning the use of postal services in The Bahamas coupled with the need to increase the amount of research conducted in The Bahamas suggests that there is a strong need for further research in this area. Clearly, there is room for further work to examine ways to modify the simple postal survey to increase response rates in The Bahamas. Studies that provide 
baseline data about the use of postal services in The Bahamas could serve to inform the decisions that researchers make when designing methodologies for their studies. For example, it would be useful to know the amount and characteristics of persons who use postal services. How frequently persons residing in The Bahamas use these postal services and why, are all useful data to collect. Researchers, however, might wish to exercise caution when using such data to make decisions about their choice of research design and methodology because these types of data are not constant and are subject to fluctuations and change. Perhaps one of the most useful approaches to gaining valuable information about data collection approaches and methods in The Bahamas would be for researchers to report (as a part of studies they conduct) on their experiences and/or encounters with data collection tools such as the postal survey.

\section{References}

Anonymous (n.d.). Postal surveys in industrial market research. Where they will work and where not, factors affecting the response rate. Business 2 Business Market Research Specialists.Retreived3rd September 2002. http:// www.b2binternational.com/article80/htlm.

Batelco (n.d.). Bahamas code routing guide. Nassau, The Bahamas: Bahamas Telecommunications Company.

Blankenship, A. B., Breen, G. E. \& Dutka, A. (1998). State of the art marketing research. Chicago, Illinois: Second edition, NYC Business Books.

Clerk, T. J., Khan, K. S. \& Gupta, J. K. (2001). Effect of paper quality on the response rate of a postal survey: A randomised controlled trial. ISRCTN 32032031.BMC Medical Research Methodology 1: 12. Abstract retrieved 3rd September 2002. http://www.biomedcentral.com/1471-22881/1/12/ abstract.

Cochran, W. G. (1977). Sampling techniques. 3rd edition. New York: John Wiley \& Son Inc.

Department of Statistics (1997). The report of the 1990 census of housing and population. Vol. II. Housing characteristics. Nassau, The Bahamas: Ministry of Economic Development.

Department of Statistics (1999). Statistical Abstract 1999. Nassau, The Bahamas: Department of Statistics, Ministry of Economic Development.

Department of Statistics (2002). Report on the 2000 census of population and housing. Nassau, The Bahamas: Ministry of Economic Development.

Green, K. E., Boser, J. A. \& Hutchinson, S. R. (n.d.). Postal survey design variables and response rates. Retrieved 2nd September 2002. www.etsu.edu/ educator/elpa/surveyed/primer/mailserv.htm.

Harvard School of Public Health (2001). Survey shows Americans not panicking over anthrax. Retrieved 3rd September 2002. www.researchmatters. harvard.edu/story.php\%3Farticle_id\%3D326+postal+survey\&hl=en\&ie=UT F-8.

Herek, G. M.(2002). A Brief Introduction to Sampling. Retrieved 13th September 2002. http://psychology.ucdavis.edu/rainbow/html/fact_ sample.html\#types.

Manchester Information \& Associated Services (2001) Welsh Health Survey. Manchester Computing University of Manchester. Retrieved 3rd September 2002. www.mimas.ac.uk/surveys/whs/whs_info.html.

Margetts, Barrie M. \& Nelson, Michael (1991). Design Concepts in Nutritional Epidemiology. New York: Oxford University Press.

National Association for Amateur Radio (2001). Have the recent anthrax post- 
al incidents affected your QSLing habits? Retrieved 3rd September 2002. www.arrl.org/survey.php3?pollnr=103.

Pirotta, M., Gunn, J., Farish, S. Karabatsos, G. (1999). Primer postcards improve postal survey response rates. Austr. N. Z. J. Public Health. 23: 196-197. Abstract retrieved 3rd September 2002. http://www.phaa.net.au /anzjph/apr99/232196.htm.

Samuels, D. (n.d.). Science and Technology Indicators. Submitted to ECLAC, Trinidad. Unpublished manuscript.

Sheridan, J. \& Strang, J. (1998). Late responders and non-responders to a postal survey questionnaire: analysis of potential further response and non-response bias. International Journal of Pharmacy Practice. 6 170-5. Abstract: retrieved 4th September 2002. http://www.pharmj.com/IJPP/ Abstracts/199809/sheridan/html.

Survey and Statistical Research Centre (n.d.). Data collection. Retrieved 3rd September 2002. http://www.shu.ac.uk/schools/cms/ssrc/dcollect.html

Vanderpool, J. (2002). Reflections on public opinion polling in The Bahamas: Academic research perspectives. Paper presented at the April Research Edge Forum. The College of The Bahamas at Nassau.

\section{Appendix 1:}

Survey form on community issues (emphasis on higher education issues) with a summary of the replies.

\section{Summary of responses:}

Results were available from 42 replies, but as not all forms were completed the number of responses for a particular question is variable. This is evident in the answers relating to attendance and time of departure from COB.

- $\quad 14.3 \%$ (40 replies) had attended COB. Three respondents had left COB, one each in 1979,1987 and 1989.

- Thirty-three respondents had an average of $1.97(\mathrm{se}=0.290)$ relatives at COB.

- $\quad 21.4 \%$ (40 replies) had attended colleges other than COB

- Thirty-five respondents had an average of 1.91 (se=0.675) relatives at colleges other than $\mathrm{COB}$ within The Bahamas (34 replies).

- $52.5 \%$ (40 replies) of respondents had attended colleges outside of The Bahamas.

- $\quad$ Two respondents had graduated from COB, one each in 1989, 1991.

- $\quad 100 \%$ (39 replies) thought that The Bahamas should have its own university.

- $\quad 92 \%$ (39 replies) thought that The College of The Bahamas should become the University of The Bahamas.

- $\quad$ Thirty-nine respondents worked a mean of 42.8 weeks (se=2.57)

- Forty respondents owned a mean of 2.33 motor vehicles (se=0.23). 


\section{Appendix 2:}

Survey form on community issues (emphasis on environmental issues) with a summary of the replies.

\section{Summary of the responses:}

52 replies

For context, census information (which relates to all Bahamas) is given where appropriate. However, due to the limited number of replies, we do not make formal comparisons between the figures.

- $51.9 \%$ of respondents had seen tipped-over garbage in their street this week.

- $60.8 \%$ (52 replies) had seen other litter in their street this week.

- $68.6 \%$ (51 replies) had garbage collected weekly, $21.6 \%$ twice a week and $9.8 \%$ longer than once a week.

- $100 \%$ (51 replies) thought that there was a litter problem.

- $\quad 51.9 \%$ of respondents had had at least one household member who had bought fast food in the last seven days.

- $50 \%$ of households had their own well water (c.f.: $31 \%$, Department of Statistics, 2000).

- $\quad 72.5 \%$ (51 replies) of households had cesspits, $22.5 \%$ had public sewerage, $82 \%$ had latrine (c.f.: $76 \%, 11 \%, 6 \%$ respectively, Department of Statistics, 2000).

- The mean number of people sleeping in the house was 3.35 (se=0.24) (c.f.: 73.5 people per household, Department of Statistics, 2000).

- Mean number of household members have flown in last 6 months 2.21 $10(\mathrm{se}=0.26)$.

- Mean number of motor vehicles per household 1.71 (se=0.12). 9

Joan D. Vanderpool is the Director of Research and Grants at The College of The Bahamas. She holds a Doctor of Philosophy degree in Theory and Policy Studies in Higher Education from the University of Toronto. Dr. Vanderpool's current scholarship and research interests are focused on international academic relations with an emphasis on research and academic linkages forged between higher education institutions and local and global society. She also studies the challenges faced by small nation states as they seek to develop the potential of their human and technological resources.

William Fielding has been at the Research Unit of The College of The Bahamas since 2001. He studied statistics at Exeter and Edinburgh and has worked at several UK universities as well as on aid projects in Asia and the Caribbean. 